\title{
BEBERAPA ASPEK EKOLOGI PERIKANAN DI RAWA TALIWANG, NUSA TENGGARA BARAT
}

\author{
Kunto Purnomo ' dan Didik Wahju Hendro Tjahjo"
}

\begin{abstract}
ABSTRAK
Rawa Taliwang adalah danau alami terbesar di Propinsi Nusa Tenggara Barat. Luasnya antara 584 sampai 913 ha dan kedalaman rata-rata sekitar $2 \mathrm{~m}$. Permukaan perairannya hampir seluruhnya tertutup oleh tumbuhan air. Pada tahun 1990 produksi tangkapan ikan mencapai 241,1 ton kemudian menurun menjadi 36,9 ton pada tahun 1994. Studi aspek ekologi perikanan di Rawa Taliwang dilakukan untuk mendapatkan data dan informasi tentang kondisi lingkungan perairan, potensi produksi perikanan, dan tingkat pemanfaatan sumber dayanya. Studi dilakukan pada bulan Juni dan Oktober tahun 1997. Hasil penelitian menunjukkan bahwa gulma menutupi sekitar $70-80 \%$ permukaan air. Potensi produksi ikan ditaksir sekitar $85,7-138,2$ ton/tahun dan tingkat eksploitasi sumber daya ikan mencapai $80 \%$
\end{abstract}

\begin{abstract}
Some aspects of fisheries ecology in Taliwang Lake, West Nusa Tenggara. By: Kunto Purnomo and Didik Wahju Hendro Tjahjo

Rawa Taliwang is the largest natural lake in the Province of Nusa Tenggara Barat. The total area range from 584 to $913 \mathrm{ha}$, with in average depth of $2 \mathrm{~m}$. Most of the water surface area is covered with aquatic macrophytes. In 1990 the fish yield was 241.1 ton and than declined to be 36.9 ton in 1994. Ecological studies showed that this decline of yield was caused by fishing pressures (over-fishing), eutrophication and explosion of aquatic macrophytes. Study on the aspects of fisheries ecology in Rawa Taliwang was conducted from June to October 1997. The aim of the study was to get data and information about aquatic environment quality, fish potential yield and exploitation rate of fish resource. Result of this study showed that aquatic weeds covered 70 to $80 \%$ of the water body and the fish potential yield was estimated between 85.7 to 136.2 ton per year. The exploitation rate of resource was $80 \%$ of the fish potential yield.
\end{abstract}

KEYWORDS: $\quad$ fisheries ecology, Rawa Taliwang

\section{PENDAHULUAN}

Rawa Taliwang terletak di Kabupaten Sumbawa, Propinsi Nusa Tenggara Barat (NTB). Rawa tersebut terletak pada ketinggian $13 \mathrm{~m}$ dari permukaan laut, luas antara 584 - 913 ha dan kedalaman maksimum \pm 2 m (Anonim, 1995). Sumber air berasal dari Sungai Suning dan Sungai Belo kemudian keluar melalui Sungai Brang Rea yang bermuara di Selat Alas (Gambar 1).

Beberapa tahun yang lalu, rawa yang sangat subur ini (Sarnita, 1994; Sarnita \& Kartamihardja, 1992; Sarnita \& Jangkaru, 1977) dikenal sebagai pusat penghasil ikan air tawar bagi daerah sekitarnya. Akhirakhir ini hasil tangkapan tersebut sangat merosot sehingga yang semula 2.411 ton pada tahun 1990 kemudian turun menjadi 369 ton pada tahun 1994. Penurunan tersebut diduga karena pendangkalan (Anonim, 1995) dan penutupan permukaan air oleh gulma (Anonim, 1995; Sarnita \& Kartamihardja, 1992).

Selain itu, intensitas penangkapan yang terlalu tinggi serta cara-cara penangkapan yang cukup menguras sumber daya diduga telah memberikan andil yang cukup berarti terhadap penurunan hasi tangkapan ikan (Anonim, 1995) dan kepunahan jenis ikan ekonomis penting tertentu seperti ikan tambakan

\footnotetext{
Peneliti pada Loka Riset Pemacuan Stok Ikan, Jatiluhur
}

(Helostoma temmincki) (Sarnita, 1994). Beberapa upaya untuk lebih meningkatkan hasil tangkapan ikan yang sering dilakukan adalah dengan restocking beberapa jenis ikan oleh Dinas Perikanan maupun LKMD setempat. Pada tahun 1995, Balai Penelitian Perikanan Air Tawar melalui kegiatan penelitiannya juga pernah melakukan upaya tersebut menggunakan jenis ikan sepat (Trichogaster pectoralis), lele (Clarias batrachus) dan introduksi ikan nila merah (Oreochromis niloticus) yang seluruhnya sejumlah 15.600 ekor atau seberat 0,5 ton ikan (Purnomo et al., 1996)

Penelitian ini bertujuan untuk mendapatkan data dan informasi tentang beberapa aspek ekologi perikanan seperti lingkungan perairan, potensi produksi perikanan dan tingkat pemanfaatan serta keseimbangan populasi ikannya, yang diharapkan dapat menjadi bahan pertimbangan bagi pembuat kebijakan dalam rangka optimasi pemanfaatan sumber daya ikan yang lestari di Rawa Taliwang.

\section{BAHAN DAN METODE}

Penelitian dilakukan menggunakan metode survei pada bulan Juni (musim kemarau) dan Oktober (musim hujan) tahun 1997 (Gambar 2). Lokasi 


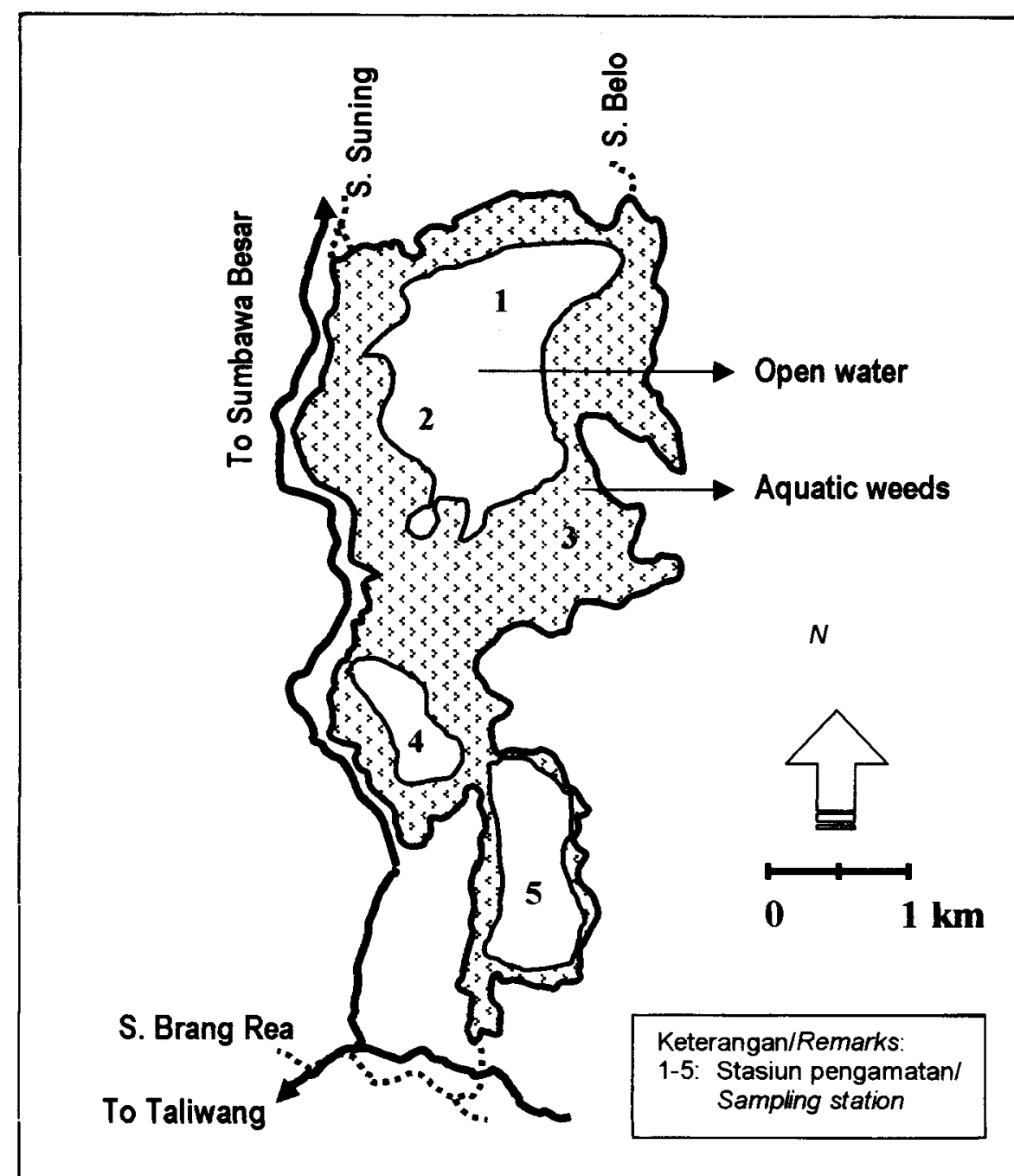

Gambar 1. Peta Rawa Taliwang.

Figure 1. Map of Taliwang Lake.

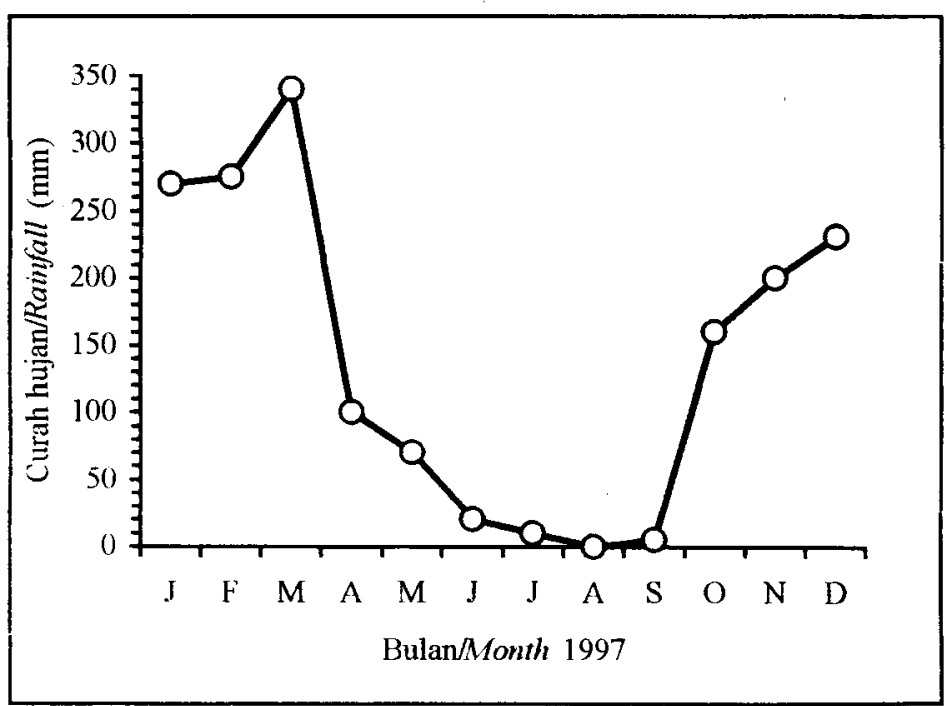

Gambar 2. Curah hujan tahun 1977 di Rawa Taliwang.

Figure 2. Rainfall at Taliwang Lake in 1997. 
sampling ditentukan secara acak sehingga masingmasing mewakili bagian utara, tengah, dan selatan perairan. Parameter kualitas air diukur secara in-situ antara lain: suhu air, kecerahan, $\mathrm{pH}, \mathrm{O}_{2}$ terlarut, $\mathrm{CO}_{2}$, dan total padatan terlarut. Pendugaan potensi lestari produksi ikan dihitung secara empirik memakai model yang banyak dipakai di daerah tropis (Moreau \& De Silva, 1991) yaitu indek morfo-edapik (Schlesinger \& Regier, 1982):

$\log M S Y=0.050 * T e m p+0.280 * \log M E I+0.236$

$\mathrm{MEI}=\mathrm{TDS} / \mathrm{z}$

di mana

MSY

Temp.

MEI

TDS

z

: hasil maksimum lestari ( $\mathrm{kg} / \mathrm{ha} / \mathrm{tahun})$ suhu air $\left({ }^{\circ} \mathrm{C}\right)$,

indek morfo-edapik

total padatan terlarut

Inventarisasi gulma air bertujuan untuk mengetahui komposisi jenis dan kelimpahannya. Komposisi tersebut diukur memakai metode "quadrat" ukuran $1 \times 1 \mathrm{~m}^{2}$ (Krebs, 1978); jenis-jenis gulma air diidentifikasi dan dicatat namanya di lapangan, atau diambil sampelnya lalu diidentifikasi di laboratorium memakai buku kunci determinasi dari Fassett (1957), Mitchell \& Thomas (1972) dan Soerjani \& Wirjahardja (1973) sedangkan kelimpahannya ditentukan berdasarkan persentase penutupan (coverage) permukaan "quadrat" oleh tiap jenis gulma yang ada.

Aspek perikanan yang dikumpulkan mencakup pencatatan hasil tangkapan tiap jenis ikan yang dijual oleh nelayan di pasar ikan Kecamatan Taliwang. Kegiatan ini dilakukan setiap hari oleh dua orang enumerator. Ukuran panjang dan bobot individu tiap jenis ikan diperoleh dari hasil percobaan penangkapan ikan memakai gillnet ukuran mata antara 2,$5 ; 3,8 ; 5,0 ; 6,3 ; 7,5 ; 8,8$; dan $10,0 \mathrm{~cm}$. Setiap kali kunjungan lapangan/sampling, gillnet tersebut dipasang tiap malam dan lokasi pemasangannya ditentukan secara acak. Data jenis-jenis dan bobot ikan tersebut selanjutnya dikelompokkan menurut kebiasaan memanfaatkan ikan sebagai makanannya menjadi populasi ikan predator dan non predator Menurut Swingle (1950) status keseimbangan populasi ikan di suatu perairan harus memenuh beberapa kriteria sebagai berikut:

F/C = Ratio antara ikan non predator dan predator Nilainya antara 1,40-10,00

$Y / C=$ Ratio antara ikan non predator ukuran kecil dan ikan predator ukuran besar. Nilainya antara $0,02-4,80$.

$A_{T}=$ Persentase berat total ikan ukuran besar (non predator dan predator) terhadap total berat sampel. Nilainya antara 33,00 - 90,00

$A_{F} \quad=$ Persentase berat ikan non predator ukuran besar terhadap berat total ikan non predator Nilainya antara 18,20 - 99,60.

$I_{F} \quad=$ Persentase berat ikan non predator ukuran medium terhadap total berat sampel ikan non predator. Nilainya antara 0,00-41,40.

SF $=$ Persentase berat ikan non predator ukuran kecil terhadap total berat ikan non predator Nilainya antara $0,40-80,90$.

\section{HASIL DAN BAHASAN}

Secara umum, hasil pengukuran beberapa parameter kualitas air (Tabel 1) menunjukkan bahwa Rawa Taliwang masih baik untuk kehidupan ikan yang secara ekologis adalah spesifik rawa, walaupun tidak terlalu masam dengan nilai $\mathrm{pH}$ antara 6,0 - 7,5 Kondisi perairan tersebut tampaknya cukup stabil dan tidak terlalu berfluktuasi sebab nilai-nilai tersebut (Tabel 1) masih termasuk dalam kisaran nilai yang diperoleh dari hasil beberapa penelitian terdahulu (Anonim, 1995; Sarnita, 1994; Sarnita \& Jangkaru, 1977)

Hasil inventarisasi dan identifikasi gulma air ditemukan 16 jenis. Sampai saat ini belum ditemukan enceng gondok (Eichhornia crassipes). Jenis-jenis yang dianggap berbahaya karena pertumbuhannya yang sangat cepat ialah kiapu (Pistia stratiotes) dan kayambang (Salvinia sp). Eksplosi gulma air menyebabkan penutupan $70-80 \%$ permukaan air,

Tabel 1.

Kualitas air Rawa Taliwang

Table 1. Water quality of Taliwang Lake

\begin{tabular}{lcc}
\hline \multirow{2}{*}{ Parameter/Parameters } & \multicolumn{2}{c}{ Bulan/Months } \\
\cline { 2 - 3 } & Juni/June & Oktober/October \\
\hline Suhu udara/Air temperature $\left({ }^{\circ} \mathrm{C}\right)$ & $30.0-31.0$ & $28.0-29.5$ \\
Suhu air/Water temperature $\left({ }^{\circ} \mathrm{C}\right)$ & $31.0-32.0$ & $30.0-31.0$ \\
Kecerahan/Transparency $(\mathrm{cm})$ & $100.0-120.0$ & $50.0-80.0$ \\
$\mathrm{pH}($ unit) & $6.0-6.5$ & $7.0-7.5$ \\
$\mathrm{CO}$ & $(\mathrm{mg} / \mathrm{l})$ \\
$\mathrm{DO}(\mathrm{mg} / \mathrm{l})$ & $17.5-27.0$ & $16.5-18.0$ \\
Total padatan terlarut/Tot. dissolved solid (mg/l) $\quad$ Kedalaman perairan (Water depth) $1,0-2,0 \mathrm{~m}$ & 14.0 & $3.1-3.8$ \\
\hline Keterangan/Remarks: & & 77.0 \\
\hline
\end{tabular}


terutama oleh jenis-jenis berdaun lebar sebangsa teratai yaitu Nymphoides indica, Nelumbo lutea, Nymphaea pubescens, dan Caltha palustris sedangkan di dasar perairan didominasi oleh Hydrilla verticillata dan Ceratophyllum demersum (Purnomo et al., 1996).

Tabel 2. Jenis-jenis tumbuhan air di Rawa Taliwang

Table 2. Aquatic plants species in Taliwang Lake

\begin{tabular}{lll}
\hline \multicolumn{1}{c}{ Jenis/Species } & \multicolumn{1}{c}{ Nama Umum/Common Name } & Famili/Family \\
\hline Azolla pinnata & Lukut cai (Sunda), water velvet & Salviniaceae \\
Caltha palustris & Marsh marigold & Ranunculaceae \\
Ceratophyllum demersum & Ganggang (Indonesia), coontail & Ceratophyllaceae \\
Hydrilla verticillata & Ganggang (hydrilla) & Hydrocharitaceae \\
Ludwigia adscendens & Cacabean (Sunda), primrose willow & Onagraceae \\
Marsilea crenata & Semanggi (Indonesia), pepperwort & Marsileaceae \\
Monochoria vaginalis & Wewean (Jawa), monochoria & Pontederiaceae \\
Najas indica & Ganggang, bushy pond weed & Najadaceae \\
Nelumbo lutea & Teratai (Indonesia), water lily & Nymphaeaceae \\
Nymphaea pubescens & Teratai, nelumbo & Nymphaeaceae \\
Nymphoides indica & Tunjang (Indonesia), floating heart & Gentianaceae \\
Pistia stratiotes & Kayu apu, paku air (Indonesia) & Araceae \\
Polygonum barbatum & Jukut carang, smartweed & Polygonaceae \\
Sagitaria lancifolia & Arrowhead & Alismaceae \\
Salvinia molesta & Kayambang (Sunda), floating moss & Salviniaceae \\
Scirpus grossus & Wlingi (Jawa), bulrush & Cyperaceae \\
\hline
\end{tabular}

Berdasarkan data luas, kedalaman maksimum perairan dan nilai total padatan terlarut yang diperoleh (Tabel 1) serta hasil penghitungan memakai model indek morpho-edapik (Schlesinger \& Regier, 1982) diketahui bahwa potensi lestari produksi ikan di Rawa Taliwang diestimasi antara $120,3-193,9 \mathrm{~kg} / \mathrm{ha} / \mathrm{th}$ atau $85,7-138,1$ ton/tahun. Hasil tersebut tidak jauh berbeda bila dibandingkan dengan pengukuran memakai metode produktivitas primer yang memperoleh estimasi potensi sebesar 120,0 ton/tahun (Sarnita, 1994; Sarnita \& Kartamihardja, 1992). Hasil monitoring tangkapan ikan di Pasar Ikan Taliwang dari bulan Agustus - Oktober 1996 (Tabel 3) menunjukkan bahwa rata-rata hasil tangkapan ikan dari perairan Rawa Taliwang adalah sebesar $7.346 \mathrm{~kg} / \mathrm{bulan}$. Menurut Kepala Resort Perikanan Kecamatan
Taliwang, hasil tangkapan ikan yang dipasarkan hanya $\pm 80 \%$ dari total hasil tangkapan sedangkan sisanya ( $\pm 20 \%$ ) dijual di desa sekitar rawa dan di pasar Kecamatan Seteluk. Berdasarkan informasi tersebut maka total hasil tangkapan ikan dari Rawa Taliwang ialah sebesar 7,346 ton $\times 12$ bulan $\times 100 / 80$ $=110,2$ ton/tahun.

Kondisi ekologi perairan sekarang ini kurang baik akibat pendangkalan (Anonim, 1995) dan penutupan sebagian besar permukaan air oleh gulma. Hasil tangkapan yang dicapai saat ini sudah mencapai $\pm 80 \%$ dari taksiran potensinya. Oleh karena itu intensitas penangkapan harus mulai dikendalikan agar hasil tangkapan tidak lebih menurun lagi.

Tabel 3. Hasil tangkapan ikan di Rawa Taliwang bulan Agustus-Oktober 1996

Table 3. Fish yields monitored in Taliwang market during August to October 1996

\begin{tabular}{lrrrrr}
\hline \multirow{2}{*}{ Jenis Ikan/Fish species } & \multicolumn{4}{c}{ Produksi/Yield(kg) } \\
\cline { 2 - 6 } & August. & Sept. & Oct. & Total & Rataan/Average \\
\hline Mujair (Oreochromis mossambicus) & 4189.6 & 5405.5 & 5199.0 & 14794.1 & 4931.4 \\
Gabus (Channa striata) & 1338.3 & 1200.5 & 962.5 & 3501.3 & 1167.1 \\
Nila (Oreochromis niloticus) & 932.5 & 875.0 & 753.7 & 2561.2 & 853.7 \\
Belut (Fluta alba) & 2055 & 117.0 & 58.5 & 381.0 & 127.0 \\
Tawes (Barbodes gonionotus) & 81.0 & - & - & 81.0 & 81 \\
Betok (Anabas testudineus) & 234.5 & 201.5 & - & 436.0 & 218.0 \\
Sidat (Anguilla sp) & 59.0 & - & - & 59.0 & 59.0 \\
Lele (Clarias batrachus) & 43.8 & - & - & 43.8 & $\mathbf{4 3 . 8}$ \\
Sepat (Trichogaster pectoralis) & 156.3 & 23.5 & - & $\mathbf{1 7 9 . 8}$ & $\mathbf{8 9 . 9}$ \\
\hline Tot a I & $\mathbf{7 2 4 0 . 5}$ & $\mathbf{7 8 2 3 . 0}$ & $\mathbf{6 9 7 3 . 7}$ & $\mathbf{2 2 0 3 7 . 2}$ & $\mathbf{7 5 7 0 . 9}$ \\
\hline
\end{tabular}




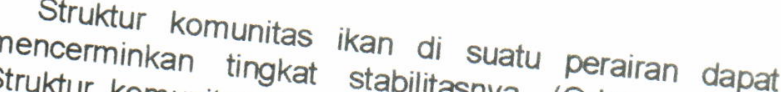
Struktur komunitas ikan di Rawilasnya (Odum, 1971). berukuran posi ikan yang bersifat Taliwang didominas dianalisis besar (Tabel 4). Dari Tat non-predator dan predator dan nilai rasio antara 4 tersebut setelah Nilai tersebut predator (F/C) sebesar 138 ikan non-

Tabel 4 Table 4 dikemukakan

bahwa keseimbang Swingle

agak kurang mangan populasi ikan mengindikasikan predator maik. Menurut Swingli Rawa Taliwang yang maksimum sebaiknya $20 \%$ (1950) populasi ikan dikenda. Sehingga popula 20\% dari total populas dikendalikan, misalnya dengan ikan predator harus tombak.

\section{an} The composition of predatory and nodator di Rawa Taliwang

Jenis ikan/Fish species Berat ikan/Fish weight

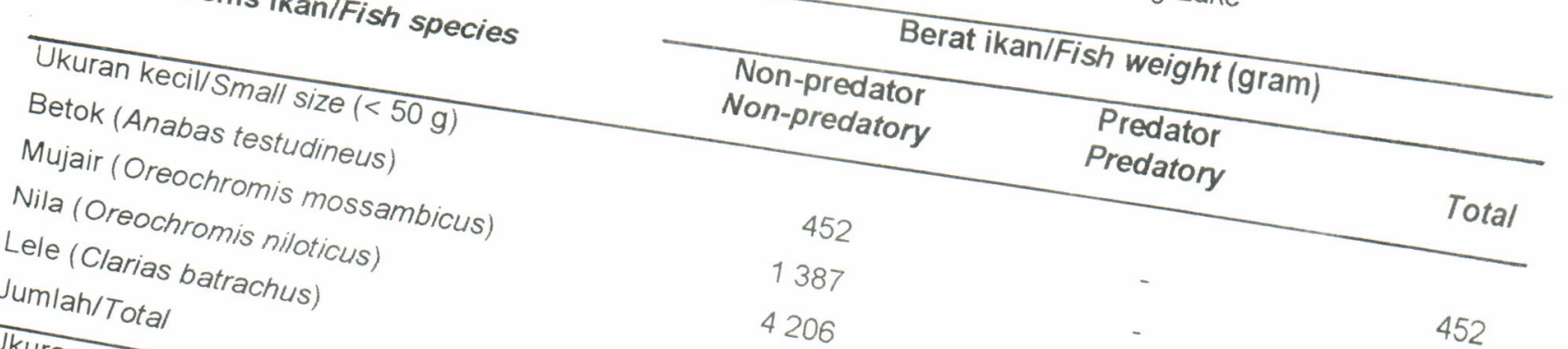

Ukuran sedanglMedum size 4206

Nila (Oreochromis niloticus)

Lele (Clarias batrachustoralis)

Jumlah/Total

Ukuran besar/Big size $>1009)$

Sepat (Trichogaster pectoralis)

Gabus (Channa btriachus)

Jumlah/Total

Total jumlah/

ctoralis)

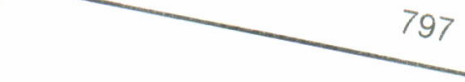

40

$40 \quad 4206$

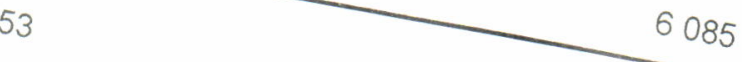

Tabel 5
Table 5

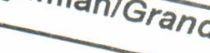

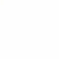
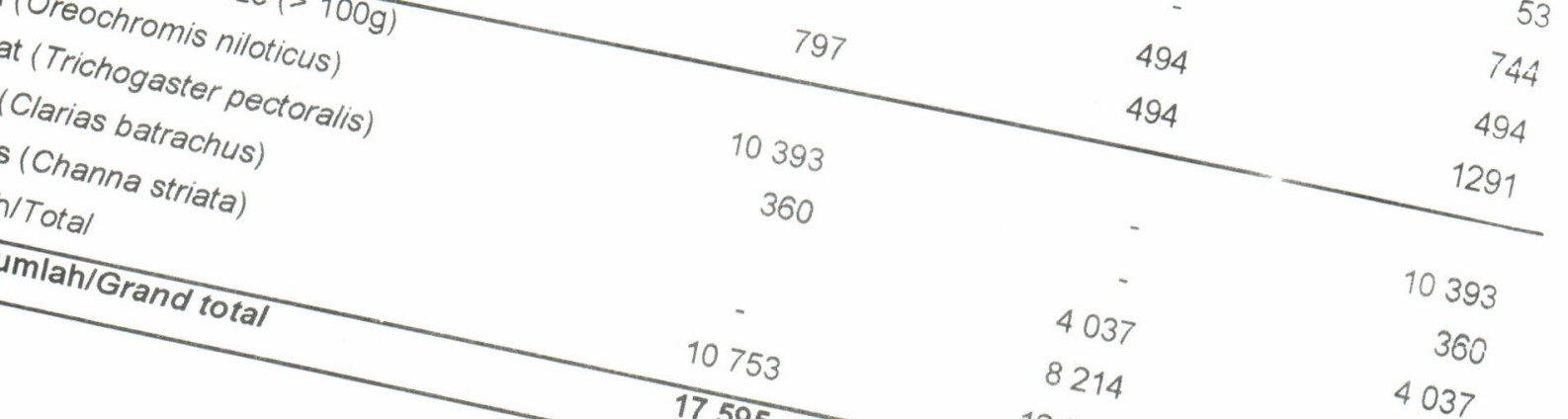

4037

8214

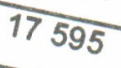

12251

The balance $p$

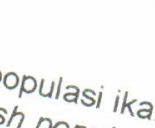

kan di Rawa

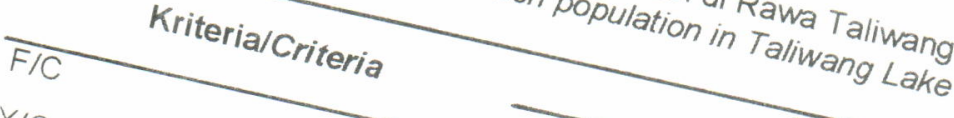

$Y / C$

AT

$A_{F}$

IF
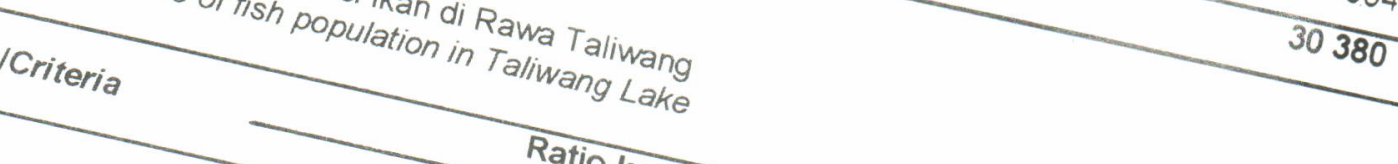

$S_{F}$ Standar/standar keseimbangan

1.40-10.00

$0.02-4.80$

33.00-90.00

$18.20-99.60$

$0.00-41.40$

10393

360

4037

8214 23004
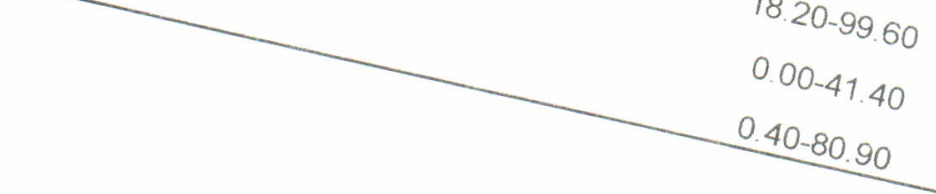

\subsection{2}

61.11
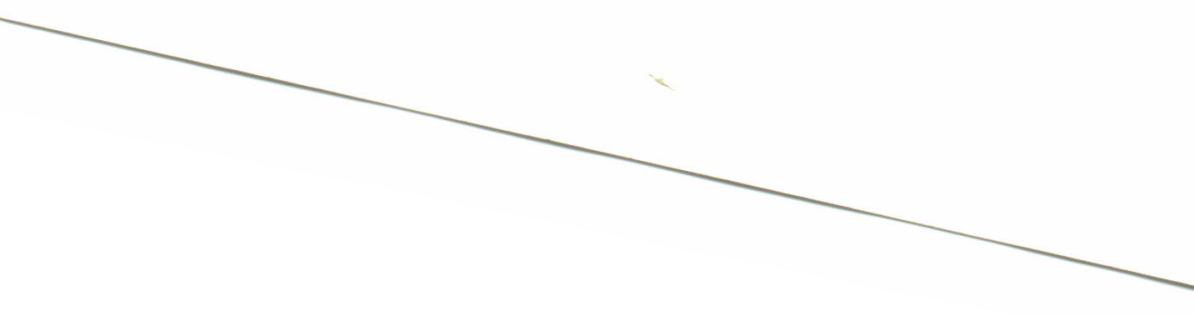
Kunto Pumomo dan Didik Wahju Hendro Tjahjo

\section{KESIMPULAN}

Kondisi perairan Rawa

tergolong kurang baik sebab sekitang secara ekologis airnya tertutup oleh gulma sekitar $70-80 \%$ permukaan ditaksir antara 85,7-138, air. Potensi produksi ikan pemanfaatan potensinya ton/tahun dan tingkat karena itu upaya penangh mencapai $80 \%$, oleh dikendalikan misalnya penangkapan saat ini perlu budi daya. Dominasi popun mengalihkan ke usaha gabus) di perairan ini perlu dikendalikan misadah mulai terasa, sehingga penangkapan memakai ya dengan lebih mendorong populasi ikan non-pradato rawaing sehinga

\section{DAFTAR PUSTAKA}

Anonim. 1995. Studi penyiapan pengelolaan dan konservasi Danau Taliwang di Kabupaten Sumbawa, Nusa Tenggara Barat. Bahan Diskusi Amythas Expert and Associates. Jakarta, 24 pp

Fassett, N.C. 1957. A manual of aquatic plants. The University of Wisconsin Press. Madison, 405 pp

Krebs, C.J. 1978. Ecology: The experimental analysis of distributions and abundance. Harper and Row. New York, $678 \mathrm{pp}$.

Mitchell, D.S. \& P.A. Thomas. 1972. Ecology of water weeds in the Neotropics. UNESCO Tech. Pap. in Hydrobiology, (12): $49 \mathrm{pp}$

Moreau, J. \& S.S. De Silva. 1991. Predictive fish yield models for lakes and reservoir of the Philippines, Sri Lanka, and Thailland. FAO Fish. Tech. Pap., (319): 42 hal.

Odum, E.P. 1971. Fundamentals of ecology. Third edition. W.B. Saunders Company. Philadelphia
London. Toronto. 574 pp.

Purnomo, K.

1996. Teknologi rehabilitasi pumto \& S. Romahon sepat, dan tambakan populasi ikan nila, lele Sumbawa. Laporan Penelitian Rawa Taliwang (Tidak dipublikasi)

Sarnita, A.S. 1994. Biologi perikanan Rawa Taliwang
dan Waduk Mamak Sumbawa Hasil Penelitian Perikanan Air Tawar. Seminar Sukabumi, 26-28 Meinan Air Tawar 1993/1994

Sarnita, A. \& Z. Jangkaru. 1977. Penelitian perikanan Rawa Taliwang dalam rangka peningkatan daya gunanya. Laporan No. 15. LPPD, Bogor

Sarnita, A. \& E.S. Kartamihardja. 1992. Hasil-hasi penelitian potensi dan tingkat pemanfaatan sumber daya perikanan air tawar di Bali dan Nusa Tenggara. Prosiding Temu Karya IImiah Dukungan Penelitian Bagi Aplikasi Pola Pengembangan Usaha Perikanan Di Nusa Tenggara. Mataram, 12 14 Agustus 1992. Pros. Puslitbangkan No. 27/1992. Pusat Penelitian dan Pengembangan Perikanan, p. 46 -- 56

Schlesinger, D.A. \& H.A. Regier. 1982. Climatic and morphoedaphic indices of fish yields from natural lakes. Trans. Am. Fish. Soc. 111:141 -- 150

Soerjani, M. \& S. Wirjahardja. 1973. Beberapa tumbuhan pengganggu air dan cara pengendaliannya. BIOTROPNR/73/060

Swingle, H.S. 1950. Relationships and dynamics of balanced and unbalanced fish populations. Agricultural Experiment Station, Alabama Polytechnic Inst. p. 1 -- 74 